\title{
Combined effects of cover crops, mulch, zero-tillage and resistant varieties on Striga asiatica (L.) Kuntze in rice-maize rotation systems
}

\author{
Meva Tahiry Randrianjafizanaka ${ }^{a}$, Patrice Autfray ${ }^{b}$, Alain Paul Andrianaivo ${ }^{c}$, Isabelle \\ Ratsimiala Ramonta ${ }^{\mathrm{a}}$, Jonne Rodenburg ${ }^{\mathrm{d}, \mathrm{e} 1}$ \\ ${ }^{a}$ Université d'Antananarivo, Faculté des Sciences, BP 906, Antananarivo, Madagascar \\ ${ }^{b}$ Centre de Cooperation Internationale en Recherche Agronomique pour le Développement (Cirad), BP \\ 319, Antsirabe, Madagascar \\ ${ }^{c}$ Centre National de la Recherche Appliquée au Développement Rural (FOFIFA), BP 1444, Antananarivo, \\ Madagascar \\ ${ }^{d}$ Africa Rice Center (AfricaRice), 01 BP 4029 ABIDJAN 01, Abidjan, Côte d'Ivoire \\ ${ }^{e}$ Natural Resources Institute (NRI), University of Greenwich, Chatham Maritime, Kent ME4 4TB, UK
}

\begin{abstract}
In low-input rice-maize rotation systems in the hills of central Madagascar, farmers deal with erratic rainfall, poor soils, high soil erosion risks and infestation by the parasitic weed Striga asiatica (L.) Kuntze. Practices combining zero-tillage with permanent soil cover by intercropped legumes and crop residue mulches - known as Conservation Agriculture (CA) - are proposed as remedy against soil and climatic constraints. Implications of these practices for $S$. asiatica are unknown. A 4-season factorial experiment compared the current farmer practice of rice - maize rotation, involving seasonal tillage and crop residue removal (CONV), with three rice - maize rotation systems following CA with different cover crops, i.e. Vigna unguiculata (cowpea) and Mucuna pruriens (CACM), Vigna umbellata (ricebean) (CARB), and Stylosanthes guianensis (CAST). Performance of two rice varieties, NERICA-4 and -9, with partial $S$. asiatica resistance, were compared with the locally popular B22. Parasite emergence time, numbers, and seed bank sizes were recorded.

In all CA practices $S$. asiatica infection was significantly reduced. Best results were obtained with Stylosanthes guianensis (CAST). This species also suppressed ordinary weeds much better than other cover crops. With CAST, average parasite emergence was delayed by 7.5 days (in rice) and 6.3 days (in maize) and infection levels were reduced by $79 \%$ (in rice) and $92 \%$ (in maize) compared to the conventional farmer practice (CONV). NERICA varieties delayed $S$. asiatica emergence by 5.7 days (NERICA-9) and 9.7 days (NERICA-4) and reduced infection levels by 57\% (NERICA9) and 91\% (NERICA-4) compared to B22. In maize the residual effect of resistance of NERICA-4 resulted in a delay of 7.5 days in $S$. asiatica emergence and a reduction of $60 \%$ in parasite numbers. The best combinations delay $S$. asiatica emergence by 17.8 days (CAST + NERICA-9) and 19.1 days (CARB + NERICA-4) and reduce the parasite infection levels by $96 \%$ (CAST + NERICA-9 or -4) to 98\% (CARB + NERICA-4) in rice, compared to $\mathrm{CONV}+\mathrm{B} 22$. After two full rice-maize rotation cycles $S$. asiatica seed numbers in the soil $(0-10 \mathrm{~cm})$ were $76 \%(\mathrm{CACM}), 78 \%$ (CAST) and $86 \%$ (CARB) lower
\end{abstract}

\footnotetext{
${ }^{1}$ Corresponding author. E-mail address: j.rodenburg@cgiar.org/j.rodenburg@greenwich.ac.uk (J.

Rodenburg).
} 
than under CONV. Even the combination of zero-tillage, crop residue mulching, cover crops and resistant rice varieties does not entirely prevent $S$. asiatica parasitism and seed bank increase. Additional measures, targeted to escaping weeds, would be required for fully effective and long-term control.

Keywords: parasitic weeds, conservation agriculture, NERICA rice varieties, Mucuna, Stylosanthes, legumes

\section{Introduction}

Maize (Zea mays L.) and rice (Oryza sativa L and O. glaberrima Steud.) are two of the most important food crops in sub-Saharan Africa (Shiferaw et al., 2011; Seck et al., 2012). Rice varieties adapted to free-draining upland soils can be grown under similar conditions as maize and both crops are therefore often grown by the same farmers, either intercropped or in rotation (Balasubramanian et al., 2007; Shiferaw et al., 2011). These farmers however face a number of — related or mutually reinforcing_ production constraints, like drought, suboptimal soil fertility and weed infestation (Balasubramanian et al., 2007; Cairns et al., 2012). Striga spp., are important weeds in both crops (e.g. Johnson et al., 1997). The two most important Striga species are S. asiatica (L.) Kuntze, with weedy forms predominantly found in Eastern and Southern Africa, and $S$. hermonthica (Del.) Benth., mostly found in sub-Saharan Africa north of the equator (Mohamed et al., 2001). Infestation by Striga is one of the main biotic production constraints in maize in Africa (Shiferaw et al., 2011; Cairns et al., 2012), with a conservatively estimated incidence of 14\% across the continent (De Groote et al., 2008). For rice the importance is less generally acknowledged (Schut et al., 2015) but the average incidence of Striga in rice is recently estimated at a conservative $12 \%$ (Rodenburg et al., 2016). Reported Striga-inflicted yield losses range from 21 to 74\% in maize (De Groote et al., 2008) and from 35 to 80\% in rice (Rodenburg et al., 2016).

In the mid-west of Madagascar, upland rice-maize rotations are often practiced on poorly textured and poorly fertile soils on sloping land and under conditions of erratic rainfall, with droughts alternated by intense rainfall events (e.g. Bruelle et al., 2015). Soil erosion by run-off therefore occurs frequently in this area (Dusserre et al., 2012). This further impoverishes the soils (Smaling et al., 1996), and facilitates weed seed dispersal (Burton et al., 2005). Striga asiatica is one of the most dominant weed species in these rice-maize rotation systems in Madagascar (Geiger et al., 1996). This, in turn, is no surprise as the presence of Striga species is often associated with poor soil fertility and erratic rainfall conditions (Kamara et al., 2014).

One of the possible strategies to address the above-described climate and soilrelated problems in cereal cropping systems is to replace the practice of seasonal soil tillage and clearance, by an intercropping, zero-tillage system with permanent - living or dead-vegetative soil cover, commonly referred to as Conservation Agriculture (Thierfelder and Wall, 2009, 2012). In mid-west Madagascar, where rice-maize rotation is the predominant system, Conservation Agriculture (CA) practices have been tested with variable outcomes, as socio-cultural and economic benefits and suitability lagged behind agronomic and environmental merits (Sester et al., 2015). Positive effects of CA were reported on rice blast (Sester et al., 2014) and white grub, a soil-dwelling Scarab beetle larvae (Ratnadass et al., 2013). It is not known whether the proposed CA strategies 
also reduce $S$. asiatica infestation, but individual components proved successful. Intercropping may reduce Striga when the intercropped non-host species can cause seed of the parasite to germinate without supporting parasitism, a principle called 'suicidal germination' (e.g. Khan et al., 2010). The intercrop canopy can also reduce Striga by increased shading and humidity and decreased temperatures (Oswald et al., 2002). Mulching has also been shown to suppress Striga parasitism (Midega et al., 2013) probably partly through similar mechanisms, while zero-tillage may prevent newly produced Striga seed to enter the soil deep enough to encounter suitable host roots in subsequent cropping seasons (van Ast et al., 2005).

In the current study, effects of a combination of these measures on $S$. asiatica were tested in an infested farmer's field in the rice-maize production zone of mid-west Madagascar. The practices were tested with rice varieties differing in resistance level. The use of resistant varieties has often been suggested as an ideal component of an integrated Striga management strategy (e.g. Yoder and Scholes, 2010), but broad-based evidence for this is still scarce. The locally predominant farmer practice of rice-maize rotation with seasonal tillage and crop residue removal is treated as the reference. The objectives were to (1) find leads for improvements of this rice-maize rotation system that could benefit smallholder farmers, (2) quantify effects of different rice varieties, management practices and combinations of varieties and practices on $S$. asiatica control and (3) discuss possible factors explaining such effects.

\section{Materials and Methods}

\subsection{Study site}

During four cropping seasons — in the period from December 2011 to April 2015- a factorial experiment was conducted at a farmer's field in Ivory, in mid-west Madagascar. The field was located at $19^{\circ} 33^{\prime} 26^{\prime}$ 'S and 46 24'55' $\mathrm{E}$. The elevation at this site is $930 \mathrm{~m}$ above sea level.

The study area is characterized by a tropical climate of medium altitude with two well-defined seasons: the hot rainy season from November to April and the cold dry season from May to October. Temperature, radiation and rainfall data were recorded daily by an automatic meteorological station (ENERCO 404 Series, Cimel, France) at $835 \mathrm{~m}$ from the experiment. During the experiment (September to May) average monthly radiation ranged from 17 to $28 \mathrm{MJ} \mathrm{m}^{-2}$, and temperatures ranged from $17.2^{\circ} \mathrm{C}$ (night) to $30.7^{\circ} \mathrm{C}$ (day), with monthly averages between 21 and $25^{\circ} \mathrm{C}$, and similar monthly fluctuations across seasons. The cumulative rainfall during the experiment was $976 \mathrm{~mm}$ in Season 1, 1,452 $\mathrm{mm}$ in Season 2, 1,194 $\mathrm{mm}$ in Season 3 and 1,814 $\mathrm{mm}$ in Season 4 (Figure 1). The long-term annual mean rainfall is $1,307 \mathrm{~mm}$.

The soil is characterized as clay-loam Oxisol (USDA) with a clay-silt-sand composition of $34-39-27 \%$ in the top layers $(0-10 \mathrm{~cm})$. The soil was generally moderately deficient in nutrient and organic matter content, with $17.2 \mathrm{~g} \mathrm{~kg}^{-1}$ of C, $1.4 \mathrm{~g}$ $\mathrm{kg}^{-1}$ of $\mathrm{N}$ (total) and $2.5 \mathrm{mg} \mathrm{kg}^{-1}$ of available $\mathrm{P}$ (Olsen). Soil $\mathrm{pH}\left(\mathrm{H}_{2} \mathrm{O}\right)$ was 5.3. Nutrient content of applied cattle manure was $0.93 \% \mathrm{~N}, 11.9 \% \mathrm{C}, 0.14 \% \mathrm{P}, 0.94 \% \mathrm{~K}, 0.50 \% \mathrm{Ca}$, and $0.20 \% \mathrm{Mg}$. The field was positioned on a moderate slope (0 to 5\%). Experimental replicates were laid out along this gradient with Replicate 1 on the top and Replicate 6 at the bottom of the slope. 


\subsection{Experimental treatments and plant material}

The locally predominant farmer practice of rice-maize rotation with seasonal tillage and removal of crop residues (henceforward referred to as conventional practice, or CONV) is compared with three rice-maize rotation systems following conservation agriculture (CA) principles. The three CA practices were (1) CACM: intercropping maize with cowpea (Vigna unguiculata [L.] Walp. cv David) and Mucuna (Mucuna pruriens [L.] DC. cv CTAS MU1); (2) CARB: intercropping maize with ricebean (Vigna umbellata [Thunb.] Ohwi \& Ohashi cv. CTAS tsiasisa) and (3) CAST: intercropping rice and maize with Stylosanthes (Stylosanthes guianensis [Aubl.] Sw., cultivar CIAT 184). The choice of cover crop species is based on agronomic and weed control principles. For Striga control and soil conservation a suitable intercrop for these rice-maize rotation systems should have good soil coverage during the maize crop, produce enough biomass for mulch during the rice crop and also improve soil fertility. Suitable cover crop species for these systems and soil types, responding to that profile, were identified by Naudin et al. (2015a). From the range of crops they identified, three contrasting species, or species combinations were selected: (1) the short-cycle annual legumes Vigna unguiculata (cowpea) Mucuna pruriens (velvetbean), (2) the long-cycle annual legume Vigna umbellata (ricebean) and (3) the perennial legume Stylosanthes guianensis (stylo). Among these species, Velvet bean and cowpea have already shown to reduce Striga spp. problems (Oswald et al., 2002; van Mourik et al., 2008; Kiwia et al., 2009). Based on agronomic reasons (e.g. crop-crop competition, ease of management), Naudin et al. (2015a) also recommended rice not to be intercropped with the annual legumes cowpea, mucuna and ricebean. Maize, on the other hand is suitable for intercropping because of the relative large inter-plant spaces.

In all CA practices soils were only tilled at the onset of the first season and no longer thereafter and all crop residues - except grains, panicles and pods - were left on the field as mulch after harvest of crops and intercrops.

Three upland rice varieties were compared simultaneously: (1) the locally popular but Striga-susceptible B22, a Brazilian rice variety, and the more recently introduced NERICA (New Rice for Africa) varieties (2) NERICA-4 and (3) NERICA-9. NERICA-4 is Striga-resistant, while NERICA-9 is moderately Striga-resistant (Rodenburg et al., 2015). The NERICA varieties are offspring from interspecific crosses between the Asian rice species Oryza sativa L. and the African rice species Oryza glaberrima Steud. (Jones et al., 1997). The maize variety used in this study was IRAT 200 , a commercially available but Striga-susceptible variety. It was sourced from Ambatolahy, a nearby village (193' $\left.37^{\prime \prime} \mathrm{S}-46^{\circ} 26^{\prime} 37^{\prime \prime} \mathrm{E}\right)$.

\subsection{Experimental design}

The experiment was laid-out following a split-plot design with cropping practices randomly assigned to the main plots and rice varieties randomly assigned to the sub-plots, in six replicates. Hence, rice variety was used as a sub-treatment factor, even in seasons with maize (to study potential carry-over effects of $S$. asiatica resistance). In order to study the main crops of this rotation each year, the main plots were divided in two, with rice grown in one part and maize in the other part.

The size of the main plot, representing a cropping practice, was $270 \mathrm{~m}^{2}(15 \times 18$ $\mathrm{m})$. Each of the three sub-plots, representing a rice variety, measured $90 \mathrm{~m}^{2}(5 \times 18 \mathrm{~m})$. 
Each sub-plot, comprised one $S$. asiatica counting area of $37.8 \mathrm{~m}^{2}(4.2 \times 9 \mathrm{~m})$ for rice and $36 \mathrm{~m}^{2}$ (4 x $\left.9 \mathrm{~m}\right)$ for maize, four non-overlapping $S$. asiatica seed bank sampling areas of 6 $\mathrm{m}^{2}(2 \times 3 \mathrm{~m})$ and two non-overlapping soil sampling areas of $3 \mathrm{~m}^{2}(0.6 \times 5 \mathrm{~m})$ for chemical analyses.

\subsection{Field preparations and crop management}

The experimental field was under fallow vegetation during the two years preceding the experiment. The field was ploughed in October 2011, using a tractor-mounted disc plow, and cleaned from all fallow vegetation by hand. After that, harrowing to a finer tilt was done using a tractor-mounted tooth peg harrow. In plots following conventional practice, from the second season onwards, tillage was done manually using a so-called angady, a local traditional soil tillage tool, at a depth of $15-20 \mathrm{~cm}$. In plots following CA practices, the soil was not tilled beyond soil preparation for the first season.

Rice was sown from 5 to 8 December in 2011, 19 to 23 November in 2012, 18 to 22 November in 2013 and 24 to 28 November in 2014, at a planting distance of $20 \mathrm{~cm}$ in the row and $30 \mathrm{~cm}$ between the rows, at 6-7 seeds per planting hole. Maize was sown at the same dates as rice, in paired rows with $50 \mathrm{~cm}$ between the two rows of one pair and $150 \mathrm{~cm}$ between two pairs, at a rate of two seeds per hole and a within-row plant distance of $50 \mathrm{~cm}$.

For CACM, cowpea was sown at the same time as maize, between two pairs of maize rows, at a rate of two seeds per hole and a plant distance of $25 \mathrm{~cm}$ in the row and $50 \mathrm{~cm}$ between the rows, resulting in two cowpea rows between each pair of maize. To enhance cover crop biomass production, at 50 days after sowing (DAS) one row of Mucuna was sown between two rows of cowpea and another row between the two rows of a pair of maize, at a rate of two seeds per hole. Mucuna was sown in relay with cowpea to maintain a vegetative ground cover beyond cowpea harvest and to avoid competition between the two cover crops.

For CARB, ricebean was sown at the same time as maize with two rows of ricebean between two pairs of maize rows, at a rate of 5-7 seeds per hole and a planting density of $50 \mathrm{~cm}$ in the row and $50 \mathrm{~cm}$ between rows. To increase the biomass of ricebean an additional row was sown in between the paired rows of maize at 50 DAS.

In plots following cropping practice CAST, in the first year, Stylosanthes was sown at 14 DAS at $40 \mathrm{~cm}$ in the row and $30 \mathrm{~cm}$ between rows, between the rice or maize at a seeding rate of about $5 \mathrm{~kg} \mathrm{ha}^{-1}$. Stylosanthes was sown later to provide the main crop with a head start reducing early-season crop competition. Between two rows of rice, one row of Stylosanthes was sown, with $15 \mathrm{~cm}$ between the Stylosanthes and the rice. Between two pairs of maize rows three rows of Stylosanthes were grown, with $45 \mathrm{~cm}$ between the maize and the Stylosanthes at each side. Between two seasons (i.e. the period May-December), Stylosanthes was rolled and slashed back three times: (1) At the end of the rainy season, around mid-June, (2) Half-way the dry season, mid-September and (3) Before sowing of the next crop, at the beginning of November. Stylosanthes plants were allowed to re-sprout and seeds produced in the previous year were allowed to germinate and grow.

In each season and for all practices, cattle manure was applied at sowing at a rate equivalent of $11 \mathrm{t} \mathrm{ha}^{-1}$ in the rice plots and $5.5 \mathrm{t} \mathrm{ha}^{-1}$ in the maize plots, following local practices. No inorganic fertilizers were applied. All plots were hand weeded two times 
during the season, at 46-50 and 74-85 DAS, whereby all weeds other than Striga were removed.

\subsection{Measurements and observations}

To assess treatment effects on soil fertility, after Season 1 (June 2012) and after Season 4 (June 2015) nine soil samples (0-10 cm depth) were done in each maize and rice plot. Each sample contained $196.3 \mathrm{~cm}^{3}$ of soil. For each plot a composite sample of $500 \mathrm{~g}$ airdried and sieved (at $2 \mathrm{~mm}$ ) soil was extracted for nitrogen ( $\mathrm{N}$ Kjeldahl), and available phosphorus (Olsen) assessment at the Radio-Isotope Laboratory of the University of Antananarivo in Madagascar.

To assess treatment effects on the $S$. asiatica seed bank in the soil, sampling of the upper $10 \mathrm{~cm}$ of soil was done at the onset of the experiment in rice sub-plots (November 2011), and at the end of the experiment (June 2015), in the same sub-plots, after the maize crop harvest (hence after two complete cycles of the rice-maize rotation). At both dates six soil samples each $1,130.4 \mathrm{~cm}^{3}$ were taken per sub-plot- from fixed locations outside areas used for other sampling - and mixed into one composite sample per replicate from which $100 \mathrm{~g}\left(106 \mathrm{~cm}^{3}\right)$ was sub-sampled for $S$. asiatica seed extraction and analysis following Hartman and Tanimonure (1991).

Striga asiatica emergence (i.e. first cotyledon appearance) dates were registered, each season in both crops except for the first season in maize. Aboveground S. asiatica numbers were assessed at 70, 90 and 110 days after sowing (DAS) from the central 37.8 $\mathrm{m}^{2}$ (rice) and $36 \mathrm{~m}^{2}$ (maize) areas. To investigate treatment effects on ordinary weeds, biomass of weeds other than S. asiatica was assessed in the fourth season (2014-2015) from four $1.0 \times 0.9 \mathrm{~m}$ areas within the central area per sub-plot. These weeds were sampled twice, just prior to each manual weeding intervention, and were oven-dried during 48 hours at $60^{\circ} \mathrm{C}$ for dry matter assessment.

\subsection{Analyses}

For S. asiatica emergence dates (E-date) data were expressed as days after sowing (DAS). Cases where $S$. asiatica was not observed were treated as missing data. Based on emerged $S$. asiatica counts at three dates (70,90 and 110 DAS) the maximum aboveground $S$. asiatica numbers were assessed, and this parameter (NSmax) was used for further analysis. All data were checked for homoscedasticity and normality following Sokal and Rohlf (1995). NSmax was subjected to logarithmic (Log10) transformations, following $(\log [X+\mathrm{C}])$, where $X$ was the original, individual observation and $\mathrm{C}$ was set to 1.0. Data on aboveground parameters (E-date, NSmax and Weed Biomass) were subjected to ANOVA, using a mixed model where Season, Cropping Practice and Variety - for Striga parameters - and Weeding Time, Cropping Practice and Variety - for ordinary weed biomass - were considered as fixed effects and Cropping Practice $\times$ Replicate as random effect (following the split-plot experimental design). Soil fertility parameters (total $\mathrm{N}$ and available $\mathrm{P}$ ) were subjected to ANOVA, using a mixed model, with Time (Season 1, Season 4) and Cropping Practice as fixed effects and Cropping Practice $\times$ Replicate as random effect. Adjusted means of all parameters were compared by using Fisher's LSD test. Means and LSD values presented in the paper are backtransformed when necessary. Data on aboveground parameters were analyzed with XLSTAT version 2014.5.03 (MS Excel, 2014). 
Striga asiatica seed numbers extracted from the soil after four experimental seasons (two rotation cycles), were analyzed using a generalized linear mixed model with a negative binomial distribution to account for the count data. Seed numbers prior to the experiment (S0) were used as co-variable and we conducted an ANCOVA to test whether they (S0) affected the seed numbers after four seasons. In case this was not significant, an ANOVA was performed, with rice variety (V) and Cropping Practice (CP) as fixed effects and Replicate as random effect, followed by a comparison of means - when effects were significant - using Tukey's honest significant difference test. Striga asiatica seed data were analyzed using SAS/STAT software, Version 9.2 of the SAS System for Windows (SAS Institute, 2011).

\section{Results}

\subsection{Soil nitrogen and phosphorus changes}

No significant two-way interaction effects between time and cropping practice were observed on total soil nitrogen or available soil phosphorus. Among main effects, only time had a significant $(\mathrm{F}=35.53 ; P=0.002 ; \mathrm{df}=1)$ effect on total soil nitrogen content. In 2011 , mean $\mathrm{N}$ content $(0-10 \mathrm{~cm})$ was $1.433 \mathrm{~g} \mathrm{~kg}^{-1}$, and this significantly increased to $1.685 \mathrm{~g} \mathrm{~kg}^{-1}$ in 2015 . No time or cropping practice effects on available phosphorus were observed.

\subsection{Striga asiatica emergence dates in rice and maize}

Table 1 shows significant main effects of season $(P<0.0001$ in rice; $P=0.002$ in maize) and rice variety on dates of first $S$. asiatica emergence in rice $(P<0.0001)$ and maize following rice $(P<0.01)$. Cropping practice only had a near-significant effect on $S$. asiatica emergence dates in rice $(P=0.07)$. Season $\times$ rice variety and cropping practice $\times$

rice variety interaction effects on $S$. asiatica emergence dates were significant in rice only $(P<0.05$; Table 1$)$. No other significant interactions were observed.

First $S$. asiatica emergence dates ranges from 69 (Season 1) to 76 (Season 4) DAS in rice and from 60 (Season 2) to 68 DAS (Season 3) in maize (Table 2). Across seasons, $S$. asiatica emergence is earliest in plots with rice variety B22 (67 DAS) and latest with NERICA-4 (77 DAS). The same effect is observed in maize plots preceded by rice, with first emergence at 60 DAS in plots following B22, and 68 DAS in plots following NERICA-4.

In rice, across seasons, $S$. asiatica emerged earliest with variety B22 under CONV (62 DAS), and latest with NERICA-4 following CARB (81 DAS) and with NERICA-9 following CAST (79 DAS).

\subsection{Aboveground $S$. asiatica densities in rice}

Significant season, cropping practice and rice variety main effects $(P<0.0001)$ were observed on aboveground $S$. asiatica plant densities (maximum number $\mathrm{m}^{-2} ;$ NSmax) in rice $($ Table 1$)$. Season $\times$ cropping practice $(\mathrm{P}=0.006)$, season $\times$ rice variety and cropping practice $\times$ rice variety $(P<0.0001)$ interaction effects on NSmax were also significant.

CAST had the lowest $S$. asiatica densities among cropping practices, followed by CARB (Table 3). Under conventional practice (CONV), the $S$. asiatica density across seasons was significantly higher than under any CA practices, but evaluated per season, only CAST resulted in consistently reduced parasite densities compared to CONV. 
Relative to CONV, S. asiatica densities were on average reduced by $24 \%$ following CACM, by $53 \%$ following CARB and by $79 \%$ following CAST.

Striga asiatica densities under NERICA-9 and NERICA-4 were significantly lower than under B22 (Table 3). The difference between B22 and moderately resistant NERICA-9 was only significant in the two last seasons, when $S$. asiatica infection levels were generally higher. The more resistant variety NERICA-4 had significant lower infection levels than B22 throughout the four seasons. Relative to B22, the reduction in $S$. asiatica densities was 57\% under NERICA-9 and 91\% under NERICA-4. The $S$. asiatica densities under NERICA-4, in turn, were significantly lower than under NERICA-9.

Across seasons, highest $S$. asiatica densities were observed under CONV with B22. With any of the NERICA varieties under CONV these numbers were already significantly lower. Even lower infection levels were obtained when NERICA varieties were combined with CA cropping practices, although for the most resistant variety NERICA-4 - differences in S. asiatica densities across cropping practices were not significant. The best combinations were NERICA-4 under CARB, followed by CAST and CACM and NERICA-9 under CAST (Table 3). Relative to CONV with B22, infection levels were reduced by more than $95 \%$ following these combinations.

\subsection{Aboveground S. asiatica densities in maize}

Significant season, cropping practice, and rice variety main effects and season $\times$ cropping practice, cropping practice $\times$ rice variety and season $\times$ cropping practice $\times$ rice variety interaction effects (all $P<0.01$ ) were found on aboveground $S$. asiatica densities in maize (Table 3). Statistical analysis was done from Season 2 onwards, as in Season 1 the maize was not preceded by rice.

Across seasons, the conventional practice (CONV) showed significant higher $S$. asiatica infection levels than any CA practice (Table 3). Among CA practices, CAST resulted in significant lower infection levels compared to CACM and CARB. The latter practices reduced $S$. asiatica infection overall by $35 \%$, compared to CONV, whereas CAST reduced infection even by $92 \%$. CAST resulted in significant reductions in parasite infection in Season 2 and 3, but not in Season 4. The other two CA practices were only effective in Season 2.

In maize following rice variety NERICA-4, the $S$. asiatica density averaged over all three seasons, was significantly lower than in maize following rice varieties NERICA9 and B22 (Table 3). Compared to B22, densities were reduced by $20 \%$ following NERICA-9 and by $60 \%$ following NERICA-4. The most significant reduction in $S$. asiatica densities in maize was obtained with CAST in plots preceded by NERICA-9 and NERICA-4. Changing the preceding rice variety from B22 to NERICA-4 under CONV already reduced $S$. asiatica infection in maize by $79 \%$. Changing the cropping practice of maize, with $\mathrm{B} 22$ as preceding rice variety, from CONV to CAST, reduced S. asiatica infection by $95 \%$. Combining the two options - maize under CAST following NERICA4 - reduced the parasite density by $97 \%$ compared to the conventional practice following B22.

\subsection{Striga asiatica seed bank changes}

Only the cropping practice had a significant effect on $S$. asiatica seed densities after four seasons (Table 4). Striga asiatica seed densities in the soil are significantly higher after 
conventional rice-maize rotation (CONV), compared to any of the CA practices (CACM, $\mathrm{CARB}$ and CAST) while differences between CA practices were not significant (Table 4). Compared to CONV, S. asiatica seed densities in the soil can be reduced by a factor 4 (CACM) to 7 (CARB) after four seasons. None of the treatments however resulted in a decrease of the $S$. asiatica seed bank size compared to the initial situation (not shown).

\subsection{Effects of cropping practice and rice variety on ordinary weed biomass}

No significant three-way or two-way interaction effects between weeding intervention time, rice variety and cropping practice were observed on ordinary weed biomass in rice in Season 4. Among the main effects, only weeding intervention time $(\mathrm{F}=15.7 ; P=0.0001$; $\mathrm{df}=1)$ and cropping practice $(\mathrm{F}=83.5 ; P<0.0001 ; \mathrm{df}=3)$ had significant effects on weed biomass. Both CONV and CAST, had significant less weed biomass than the other two practices (Figure 2). The practice with cowpea-Mucuna (CACM) had a significant higher weed biomass than the practice with rice bean (CARB).

\section{Discussion}

This study showed that through a combination of zero-tillage, crop residue mulching and cover crops — collectively indicated as Conservation Agriculture (CA) - S. asiatica infection in a rice-maize rotation could be delayed and reduced. The best results were obtained with $S$. guianensis as cover crop and NERICA-4 as variety, whereby control effects of this resistant rice variety were noticeable in the following maize crop. Stylosanthes guianensis also proved effective in terms of ordinary weed control.

This section is broken down in a discussion on the benefits of conservation agriculture (CA) practices regarding weed and Striga control (4.1), the role that resistant varieties can play to enhance Striga control efficacy under CA (4.2) and the notion that such innovations are only relevant in areas where smallholder cereal farmers deal with similar (parasitic) weed and soil constraints as encountered in the study area (4.3).

\subsection{Can conservation agriculture contribute to (parasitic) weed control?}

Conservation agriculture (CA) is a broad term to describe the more or less simultaneous application of (1) reduced soil tillage, (2) permanent soil protection through mulching and (3) increased biodiversity through crop diversification (Scopel et al., 2013). In the current study, three CA practices, with different crop diversification options — rice rotated with a maize-cowpea-Mucuna or maize-ricebean intercrop, and rice intercropped by Stylosanthes and rotated with a maize-Stylosanthes intercrop- were compared with the conventional farmer practice of rice-maize rotation without intercropping. This study presents the first evidence that applying a CA practice significantly delays parasitism of a Striga species and reduces parasite infection levels in both rice and maize. A wide range of direct and indirect causes may underlie the observed effect of CA practices (Fig. 3). These causes can be physical, biochemical or biological, they can emerge at different levels and they can either strengthen or weaken one another. All of the CA practices, by not tilling the soil, may reduce parasite infection because less Striga seeds reach the root zone (e.g. van Ast et al., 2005). In addition, the seeds remaining at the soil surface may be prone to increased seed predation by ground beetles as shown with ordinary weed seeds (Kulkarni et al., 2015). The increased living and dead biomass of cover crops, in addition, may further increase abundance and activity of the micro-fauna and therefore 
seed predation (Pullaro et al., 2006) and decay. Because of the entanglement of the different components of CA, and the numerous potential direct and indirect effects they may unleash (as shown in Fig. 3), the contribution of individual principles cannot be assessed by this study. This is the typical weakness of many CA studies, as previously postulated by Giller at al. (2009). It is indeed essential to further investigate the effectiveness or ineffectiveness of each of the components as it would help optimizing or simplifying the approaches for smallholder farmers.

The set-up of the current study does however allow assessment of the role of different cover crop species within the CA practices, because the other treatments (zerotillage and non-removal of crop residues) are the same across practices. Cover crops may differ in their effectiveness to (1) cause suicidal germination, (2) improve soil fertility (3) and produce biomass, providing (weed-suppressive, temperature decreasing and humidity increasing) canopy and mulch.

The $S$. asiatica suppressive effect of CA practices could be due to the suicidal germination of $S$. asiatica seeds caused by the cover crops (Fig. 3). Several leguminous crops have shown to be effective trap crops for Striga species that parasitize on cereal crops (Ransom, 2000). There are studies that confirm effectiveness of cowpea (Carsky et al., 1994; Gbehounou and Adango, 2003) and Mucuna (Kiwia et al., 2009) in that respect, although the mechanisms of suppression by Mucuna are not yet revealed. Whether Stylosanthes can cause suicidal germination of $S$. asiatica is subject to further studies. For a perennial species like Stylosanthes, it would be a very effective $S$. asiatica control mechanism, as it would work during both seasons of the rotation cycle.

Leguminous cover crops may also increase soil fertility and thereby contribute to $S$. asiatica suppression. Legumes that are able to fix atmospheric nitrogen can improve soil N content after several cropping cycles (e.g. Giller, 2001) but this process requires additional phosphorus (Rotaru and Sinclair, 2009). Both N and P play important roles in the production of host-root derived strigolactones (Yoneyama et al., 2013) whereby increasing levels of these elements can reduce the production of these plant hormones and decreasing levels will do the opposite. Changes in $\mathrm{N}$ and $\mathrm{P}$ consequently affect the $S$. asiatica infection chances (Jamil et al., 2012). In the current study the changes in either soil $\mathrm{N}$ or $\mathrm{P}$, observed by comparing the situation before and after the 4-season experiment, were not significantly affected by cropping practices. Hence the observed differences in $S$. asiatica infection across cropping practices cannot be assigned to differences in soil fertility enhancing effects of these treatments.

Increased shading by the cover crops could be another explanation for $S$. asiatica suppression following CA practices (Fig. 3). Stylosanthes spp. are known for their prolific biomass production and therefore often proposed as weed control agents in tropical cereal cropping systems (Chikoye et al., 2008; Saito et al., 2010). It is likely that the $S$. asiatica control obtained by Stylosanthes, is at least partly due to this very weed suppressive ability, as the current study also shows superior control of ordinary weeds, compared to the other CA practices. Weed competition constitutes a major weakness of CA unless the ground cover would be effective enough to suppress weeds (Giller et al., 2009). The current study seems to confirm this. Averaged over four seasons, CACM and CARB produced respectively 1.3 to 1.8 times the biomass produced under CONV, while CAST produced 6.7 times as much biomass (Randrianjafizanaka, unpublished). One obvious reason for this differentiation is, again, the cycle length of cover crop species. 
While cowpea, Mucuna and ricebean are annual species that are only intercropped with maize, Stylosanthes is a perennial producing biomass in both the maize and the rice season.

\subsection{What is the combined effect of conservation agriculture and resistant varieties on $S$. asiatica?}

Clear $S$. asiatica-reducing effects of zero-tillage cropping practices with cover crops, crop residue mulching and the use of resistant rice varieties have been observed in both cycles of a rice-maize rotation system, compared to the farmer practice with the locally popular variety B22. Both a change in cropping practice and a change in rice variety contributed to this observed effect, and the different solutions have shown to be synergetic. Hence inclusion of a resistant rice variety in an integrated Striga management strategy, as previously proposed by many authors and for different crops (e.g. Kamara et al., 2008; Yoder and Scholes, 2010), proved indeed important here.

Striga asiatica resistance of the two NERICA varieties showed to be an important cause of Striga suppression under all practices. While existence of differences in Striga resistance among rice germplasm have been shown before (Johnson et al., 1997;

Rodenburg et al., 2015, 2017) their compatibility with alternative cropping practices and synergy with other Striga control options are shown here for the first time. Moreover, this is the first study to show a positive carry-over effect of resistance in rice on the infection levels in the following maize crop. Therefore, the use of resistant varieties seems a very useful component technology in crop rotation systems, where two suitable hosts of the same parasite are alternated.

An integrated Striga management strategy should ideally reduce the seed bank (Westerman et al., 2007). In the current study no variety by cropping practice interaction effects on the $S$. asiatica seed bank were observed. CA practices alone, irrespective of cover crop species, showed reduced seed bank size increments compared to the conventional practice, but no seed bank size reduction compared to the situation before the experiment. Previously, van Mourik et al. (2008) showed a limited effect of legume intercropping on the $S$. hermonthica seed bank. Seed output from the seed bank is caused by decay, predation and germination. Under CA the latter category is reduced, causing a reduced seed output. With respect to seed input, only few reproductive Striga plants per area are required to replenishment or even increase the seed bank (Rodenburg et al., 2006).

Despite differences in resistance among rice varieties, and contradicting the observed carry-over effect of resistance, the factor variety also had no significant effect on the $S$. asiatica seed bank size over time. The use of Striga-resistant host plant varieties has shown before to decrease the production of parasite seed numbers compared to susceptible varieties, without concomitant reductions in the seed bank size (Rodenburg et al., 2006). This is mainly due to the prolific seed production of Striga, with an estimated production of close to 1,200 seeds per capsule for related S. hermonthica (van Delft et al., 1997). A modeling study showed that a decrease in the Striga seed bank could only be attained with varieties with either very successful pre-attachment resistance mechanisms -i.e. low production of germination stimulants - or with a combination of resistance mechanisms that affect the parasite at later stages (Westerman et al., 2007). In the current study, despite the combination of pre- (Jamil et al., 2011) and post-attachment (Cissoko 
et al., 2011) resistance in NERICA-4, a decrease in the seed bank could not be achieved. It should be stressed however that the rice in this experiment, irrespective of the resistance level of the variety, was followed each next season by a susceptible maize crop.

Compared to the conventional combination of B22 under conventional tillage and crop removal, the combination of NERICA-4 grown in zero-tillage plots with ricebean intercropping in the previous season and mulching of crop residues - among the best combination in terms of control-, resulted in an average delay in $S$. asiatica emergence of 19 days. Also with other combinations of CA practices and improved varieties, important delays in S. asiatica emergence were obtained. Delaying Striga parasitism has proven to be an important strategy to reduce overall parasite biomass - and consequently parasite reproduction - and to minimize Striga-induced crop losses (van Ast and Bastiaans, 2006), hence this finding potentially has great significance for farmers dealing with Striga infestation.

The observations on differences in S. asiatica emergence dates and infection rates also reiterate the importance of integrating management options. With the use of a resistant variety (NERICA-4) alone, parasitism can be delayed by nearly 10 days compared to the susceptible rice variety (B22). When it is combined with the other strategies - i.e. cover crops, mulching of crop residues, zero-tillage - this delay can be almost doubled. Likewise, a change from conventional to a CA practice using ricebean or Stylosanthes, reduced infection levels by 53 and $79 \%$. The use of resistant NERICA varieties compared to the susceptible variety B22 reduced infection levels with $57 \%$ (with NERICA-9) and 91\% (NERICA-4). Combinations of these practices and varieties resulted in reductions of 96 (NERICA-9 and -4 with CAST) to $98 \%$ (NERICA-4 with CARB).

\subsection{Implications for smallholder cereal farmers in Striga-prone areas}

This study confirms the broadly accepted assumption, supported by a relatively scant body of evidence (e.g. Schulz et al., 2003; Aliyu et al., 2004; Ellis-Jones et al., 2004; Kamara et al., 2008; Tesso and Ejeta, 2011), that an integrated Striga management approach indeed works. It seems however impossible to reach $100 \%$ control, even with combinations of highly efficient technologies. For long-term beneficial effects, farmers following this approach are therefore recommended to continue uprooting escaping parasites by hand before they flower, to avoid replenishment or even a buildup of the seed bank.

Smallholder cereal farmers working in Striga-prone areas could be reluctant to adopt the practices studied here. Growing an intercrop usually requires more labor, for crop establishment and harvesting. A perennial like Stylosanthes also requires additional work, as the cover crop needs to be rolled or slashed before planting the next crop (see section 2.4) and sometimes also during the season, to avoid undesired competition with the main crop.

Mulching crop residues implies a clear trade-off with other uses of crop biomass, such as feeding cattle (Naudin et al., 2015b). Finally, an important driver for adoption of alternative crop management strategies is the level of crop yields. On this point, CA often underperforms, at least in first ten years after introduction (Giller et al., 2009). One of the reasons is that cereal crop residues have a high $\mathrm{C}: \mathrm{N}$ ratio resulting in immobilization of 
nitrogen, and additional (and costly) mineral fertilizer inputs seem therefore necessary to compensate this (Vanlauwe et al., 2014).

Conservation agriculture practices need to be adjusted to the locally prevailing conditions, to render them useful for smallholder farmers (Knowler and Bradshaw, 2007). The successful control of $S$. asiatica by practices investigated in the current study, suggests that in areas where Striga is a dominant production constraint, this strategy —or components of it - will be a good fit for smallholder farmers.

\section{Conclusion}

Conservation agriculture (CA) practices, combining leguminous cover crops with zerotillage and crop residue mulching, delay and reduce Striga asiatica infection in ricemaize rotation systems. These practices also slow down seed bank increments compared to conventional rice - maize rotations. Most effective cover crop in terms of S. asiatica control is Stylosanthes guianensis. This species also proved to be the only cover crop capable of keeping ordinary weed biomass at similar, manageable levels as under the conventional practice with seasonal tillage. The weed suppressive nature of Stylosanthes is probably due to its perennial nature and high biomass production. This is also thought to be one of the reasons for the effective $S$. asiatica suppression. However, as good $S$. asiatica control was also obtained by the CA practice with the less prolific species Vigna umbellata (ricebean), other mechanisms should be involved as well.

Striga control obtained by the agronomic practices of CA can be enhanced by integration of a Striga- resistant rice variety such as NERICA-4. Inclusion of a resistant rice variety even has a strong residual control effect, as evidenced by the reduced Strigainfection levels in the following maize crop. The combination of CA practices and a resistant variety proved however not enough to entirely prevent $S$. asiatica parasitism and seed bank increase. Additional measures, such as hand-pulling of escaping S. asiatica plants before flowering, would therefore be required for effective and long term control.

\section{Acknowledgments}

This study was funded by the CGIAR Research Program entitled Global Rice Science Partnership (GRiSP) and the African Development Bank (AfDB) as part of the project "Support to Agricultural Research for Development of Strategic Crops in Africa (SARDSC)". Roger Michellon (retired from CIRAD) and Narcisse Moussa (GSDM) are kindly acknowledged for their decisive contributions to the experimental design and technical advice and support. We thank Ibnou Dieng (AfricaRice) and Philippe Letourmy (CIRAD) for their advice and assistance with the statistical data analyses. 


\section{References}

Aliyu, L., Lagoke, S.T.O., Carsky, R.J., Kling, J., Omotayo, O., Shebayan, J.Y., 2004.

Technical and economic evaluation of some Striga control packages in maize in the Nigerian Guinea Savanna. Crop Prot. 23, 65-69.

Balasubramanian, V., Sie, M., Hijmans, R.J., Otsuka, K., 2007. Increasing Rice Production in sub-Saharan Africa: Challenges and Opportunities. Adv. Agron. 94, 55-133.

Bruelle, G., Naudin, K., Scopel, E., Domas, R., Rabeharisoa, L., Tittonell, P., 2015. Short- to mid-term impact of conservation agriculture on yield variability of upland rice: Evidence from farmer's fields in Madagascar. Exp. Agr. 51, 66-84.

Burton, M.G., Mortensen, D.A., Marx, D.B., 2005. Environmental characteristics affecting Helianthus annuus distribution in a maize production system. Agr. Ecosyst. Environ. 111, 30-40.

Cairns, J.E., Sonder, K., Zaidi, P.H., Verhulst, N., Mahuku, G., Babu, R., Nair, S.K., Das, B., Govaerts, B., Vinayan, M.T., Rashid, Z., Noor, J.J., Devi, P., Vicente, F.S., Prasanna, B.M., 2012. Maize production in a changing climate: Impacts, adaptation and mitigation strategies. In: Sparks, D.L. (Ed.), Adv. Agron., 114, 1-58.

Carsky, R.J., Singh, L., Ndikawa, R., 1994. Suppression of Striga hermonthica on sorghum using a cowpea intercrop. Exp. Agr. 30, 349-358.

Chikoye, D., Ekeleme, F., Lum, A.F., Schulz, S., 2008. Legume-maize rotation and nitrogen effects on weed performance in the humid and subhumid tropics of West Africa. Crop Prot. 27, 638-647.

Cissoko, M., Boisnard, A., Rodenburg, J., Press, M.C., Scholes, J.D., 2011. New Rice for Africa (NERICA) cultivars exhibit different levels of post-attachment resistance against the parasitic weeds Striga hermonthica and Striga asiatica. New Phytol. 192, 952-963.

De Groote, H., Wangare, L., Kanampiu, F., Odendo, M., Diallo, A., Karaya, H., Friesen, D., 2008. The potential of a herbicide resistant maize technology for Striga control in Africa. Agr. Syst. 97, 83-94.

Dusserre, J., Chopart, J.L., Douzet, J.M., Rakotoarisoa, J., Scopel, E., 2012. Upland rice production under conservation agriculture cropping systems in cold conditions of tropical highlands. Field Crop. Res. 138, 33-41.

Ellis-Jones, J., Schulz, S., Douthwaite, B., Hussaini, M.A., Oyewole, B.D., Olanrewaju, A.S., White, R., 2004. An assessment of integrated Striga hermonthica control and early adoption by farmers in northern Nigeria. Exp. Agr. 40, 353-368.

Gbehounou, G., Adango, E., 2003. Trap crops of Striga hermonthica: in vitro identification and effectiveness in situ. Crop Prot. 22, 395-404.

Geiger, U., Kroschel, J., Sauerborn, J., 1996. Striga asiatica, a problem in the Middle West of Madagascar. In: Moreno, M.T., Cubero, J.I., Berner, D.K., Joel, D., Musselman, L.J., Parker, C. (Eds.), Advances in parasitic research.Proceedings of the Sixth International Parasitic Weed Symposium, Sevilla, pp. 479-486.

Giller, K., 2001. Nitrogen fixation in tropical cropping systems. CAB International, Wallingford, Oxfordhire, UK.

Giller, K.E., Witter, E., Corbeels, M., Tittonell, P., 2009. Conservation agriculture and smallholder farming in Africa: The heretics' view. Field Crop. Res. 114, 23-34. 
Hartman, G.L., Tanimonure, O.A., 1991. Seed populations of Striga species in Nigeria. Plant Dis. 75, 494-496.

Institute, S., 2011. The SAS system for Windows; Version 9.2. SAS Institute Inc., Cary, $\mathrm{NC}$, USA.

Jamil, M., Kanampiu, F.K., Karaya, H., Charnikhova, T., Bouwmeester, H.J., 2012. Striga hermonthica parasitism in maize in response to $\mathrm{N}$ and $\mathrm{P}$ fertilisers. Field Crop. Res. 134, 1-10.

Jamil, M., Rodenburg, J., Charnikhova, T., Bouwmeester, H.J., 2011. Pre-attachment Striga hermonthica resistance of New Rice for Africa (NERICA) cultivars based on low strigolactone production. New Phytol. 192, 964-975.

Johnson, D.E., Riches, C.R., Diallo, R., Jones, M.J., 1997. Striga on rice in West Africa; crop host range and the potential of host resistance. Crop Prot. 16, 153-157.

Jones, M.P., Dingkuhn, M., Aluko, G.K., Semon, M., 1997. Interspecific Oryza sativa L. X O. glaberrima Steud. progenies in upland rice improvement. Euphytica 94, 237-246.

Kamara, A.Y., Ekeleme, F., Jibrin, J.M., Tarawali, G., Tofa, I., 2014. Assessment of level, extent and factors influencing Striga infestation of cereals and cowpea in a Sudan Savanna ecology of northern Nigeria. Agr. Ecosyst. Environ. 188, 111121.

Kamara, A.Y., Ellis-Jones, J., Amaza, P., Omoigui, L.O., Helsen, J., Dugje, I.Y., Kamai, N., Menkir, A., White, R.W., 2008. A participatory approach to increasing productivity of maize through Striga hermonthica control in northeast Nigeria. Exp. Agr. 44, 349-364.

Khan, Z.R., Midega, C.A.O., Bruce, T.J.A., Hooper, A.M., Pickett, J.A., 2010. Exploiting phytochemicals for developing a 'push-pull' crop protection strategy for cereal farmers in Africa. J. Ex. Bot. 61, 4185-4196.

Kiwia, A., Imo, M., Jama, B., Okalebo, J.R., 2009. Coppicing improved fallows are profitable for maize production in Striga infested soils of western Kenya. Agroforest. Syst. 76, 455-465.

Knowler, D., Bradshaw, B., 2007. Farmers' adoption of conservation agriculture: A review and synthesis of recent research. Food Pol. 32, 25-48.

Kulkarni, S.S., Dosdall, L.M., Spence, J.R., Willenborg, C.J., 2015. Depth of Seed Burial and Gender Influence Weed Seed Predation by Three Species of Ground Beetle (Coleoptera: Carabidae). Weed Sci. 63, 910-915.

Midega, C.A.O., Pittchar, J., Salifu, D., Pickett, J.A., Khan, Z.R., 2013. Effects of mulching, $\mathrm{N}$-fertilization and intercropping with Desmodium uncinatum on Striga hermonthica infestation in maize. Crop Prot. 44, 44-49.

Mohamed, K.I., Musselman, L.J., Riches, C.R., 2001. The genus Striga (Scrophulariaceae) in Africa. Ann. Mo. Bot. Gard. 88, 60-103.

Naudin K, Husson O, Scopel E, Auzoux S, Giner S, Giller KE, 2015a. PRACT (Prototyping Rotation and Association with Cover crop and no Till) - a tool for designing conservation agriculture systems. Eur. J. Agron. 69, 21-31. 10.1016/j.eja.2015.05.003

Naudin, K., Bruelle, G., Salgado, P., Penot, E., Scopel, E., Lubbers, M., de Ridder, N., Giller, K.E., 2015b. Trade-offs around the use of biomass for livestock feed 
and soil cover in dairy farms in the Alaotra lake region of Madagascar. Agr. Syst. 134, 36-47.

Oswald, A., Ransom, J.K., Kroschel, J., Sauerborn, J., 2002. Intercropping controls Striga in maize based farming systems. Crop Prot. 21, 367-374.

Pullaro, T.C., Marino, P.C., Jackson, D.M., Harrison, H.F., Keinath, A.P., 2006. Effects of killed cover crop mulch on weeds, weed seeds, and herbivores. Agr. Ecosyst. Environ. 115, 97-104.

Ransom, J.K., 2000. Long-term approaches for the control of Striga in cereals: field management options. Crop Prot. 19, 759-763.

Ratnadass, A., Randriamanantsoa, R., Rajaonera, T.E., Rabearisoa, M.Y., Rafamatanantsoa, E., Moussa, N., Michellon, R., 2013. Interaction between cropping systems and white grub (Coleoptera: Scarabeoidea) status (pest or beneficial) on upland rice. Cah. Agr. 22, 432-441.

Rodenburg, J., Bastiaans, L., Kropff, M.J., van Ast, A., 2006. Effects of host plant genotype and seedbank density on Striga reproduction. Weed Res. 46, 251263.

Rodenburg, J., Cissoko, M., Kayeke, J., Dieng, I., Khan, Z.R., Midega, C.A.O., Onyuka, E.A., Scholes, J.D., 2015. Do NERICA rice cultivars express resistance to Striga hermonthica (Del.) Benth. and Striga asiatica (L.) Kuntze under field conditions? Field Crop. Res. 170, 83-94.

Rodenburg, J., Demont, M., Zwart, S.J., Bastiaans, L., 2016. Parasitic weed incidence and related economic losses in rice in Africa. Agr. Ecosyst. Environ. 235, 306317.

Rodenburg J., Cissoko M., Kayongo N., Dieng I., Bisikwa J., Irakiza R., Masoka I., Midega C.A.O., Scholes J.D., 2017. Genetic variation and host-parasite specificity of Striga resistance and tolerance in rice: the need for predictive breeding. New Phytol. 214, 1267-1280.

Rotaru, V., Sinclair, T.R., 2009. Interactive influence of phosphorus and iron on nitrogen fixation by soybean. Environ. Exp. Bot. 66, 94-99.

Saito, K., AzomaA, K., Oikeh, S.O., 2010. Combined effects of Stylosanthes guianensis fallow and tillage management on upland rice yield, weeds and soils in southern Benin. Soil Till. Res. 107, 57-63.

Schulz, S., Hussaini, M.A., Kling, J.G., Berner, D.K., Ikie, F.O., 2003. Evaluation of integrated Striga hermonthica control technologies under farmer management. Exp. Agr. 39, 99-108.

Schut, M., Rodenburg, J., Klerkx, L., Hinnou, L.C., Kayeke, J., Bastiaans, L., 2015. Participatory appraisal of institutional and political constraints and opportunities for innovation to address parasitic weeds in rice. Crop Prot. 74, 158-170.

Scopel, E., Triomphe, B., Affholder, F., Da Silva, F.A.M., Corbeels, M., Xavier, J.H.V., Lahmar, R., Recous, S., Bernoux, M., Blanchart, E., Mendes, I.D., De Tourdonnet, S., 2013. Conservation agriculture cropping systems in temperate and tropical conditions, performances and impacts. A review. Agron. Sustain. Dev. 33, 113-130.

Seck, P.A., Diagne, A., Mohanty, S., Wopereis, M.C.S., 2012. Crops that feed the world 7: Rice. Food Sec. 4, 7-24. 
Sester, M., Craheix, D., Daudin, G., Sirdey, N., Scopel, E., Angevin, F., 2015. Assessment of the sustainability of conservation agriculture cropping systems in Madagascar (Alaotra Lake) using MASC-Mada. Cah. Agr. 24, 123-133.

Sester, M., Raveloson, H., Tharreau, D., Dusserre, J., 2014. Conservation agriculture cropping system to limit blast disease in upland rainfed rice. Plant Pathol. 63, 373-381.

Shiferaw, B., Prasanna, B.M., Hellin, J., Banziger, M., 2011. Crops that feed the world 6. Past successes and future challenges to the role played by maize in global food security. Food Sec. 3, 307-327.

Smaling, E.M.A., Fresco, L.O., deJager, A., 1996. Classifying, monitoring and improving soil nutrient stacks and flows in African agriculture. Ambio 25, 492-496.

Sokal, R.R., Rohlf, F.J., 1995. Biometry: the principles and practice of statistics in biological research. W.H. Freeman, New York, USA.

Tesso, T.T., Ejeta, G., 2011. Integrating Multiple Control Options Enhances Striga Management and Sorghum Yield on Heavily Infested Soils. Agron. J. 103, 1464-1471.

Thierfelder, C., Wall, P.C., 2009. Effects of conservation agriculture techniques on infiltration and soil water content in Zambia and Zimbabwe. Soil Till. Res. 105, 217-227.

Thierfelder, C., Wall, P.C., 2012. Effects of conservation agriculture on soil quality and productivity in contrasting agro-ecological environments of Zimbabwe. Soil Use Manage. 28, 209-220.

van Ast, A., Bastiaans, L., 2006. The role of infection time in the differential response of sorghum cultivars to Striga hermonthica infection. Weed Res. 46, 264-274.

van Ast, A., Bastiaans, L., Katile, S., 2005. Cultural control measures to diminish sorghum yield loss and parasite success under Striga hermonthica infestation. Crop Prot. 24, 1023-1034.

van Delft, G.J., Graves, J.D., Fitter, A.H., Pruiksma, M.A., 1997. Spatial distribution and population dynamics of Striga hermonthica seeds in naturally infested farm soils. Plant Soil 195, 1-15.

Vanlauwe, B., Wendt, J., Giller, K.E., Corbeels, M., Gerard, B., Nolte, C., 2014. A fourth principle is required to define Conservation Agriculture in sub-Saharan Africa: The appropriate use of fertilizer to enhance crop productivity. Field Crop. Res. 155, 10-13.

van Mourik, T.A., Bianchi, F.J.J.A., Van Der Werf, W., Stomph, T.J., 2008. Long-term management of Striga hermonthica: strategy evaluation with a spatiotemporal population model. Weed Res. 48, 329-339.

Westerman, P.R., van Ast, A., Stomph, T.J., Van Der Werf, W., 2007. Long-term management of the parasitic weed Striga hermonthica: Strategy evaluation with a population model. Crop Prot. 26, 219-227.

Yoder, J.I., Scholes, J.D., 2010. Host plant resistance to parasitic weeds; recent progress and bottlenecks. Curr. Opin. Plant Biol. 13, 478-484.

Yoneyama, K., Xie, X.N., Kisugi, T., Nomura, T., Yoneyama, K., 2013. Nitrogen and phosphorus fertilization negatively affects strigolactone production and exudation in sorghum. Planta 238, 885-894. 
Table 1. Analysis of variance of first emergence date (E-date) and maximum aboveground numbers (NSmax) of S. asiatica in rice and maize, with season $(\mathrm{S})$, cropping practice $(\mathrm{CP})$, rice variety $(\mathrm{V})$ and interactions as sources of variation.

\begin{tabular}{|c|c|c|c|c|c|c|c|c|c|c|}
\hline \multirow[b]{3}{*}{ Source } & \multicolumn{5}{|c|}{ S. asiatica in rice } & \multicolumn{5}{|c|}{ S. asiatica in maize } \\
\hline & \multirow[b]{2}{*}{$\mathrm{df}$} & \multicolumn{2}{|c|}{ E-date } & \multicolumn{2}{|c|}{ NSmax } & \multicolumn{3}{|c|}{ E-date } & \multicolumn{2}{|c|}{ NSmax } \\
\hline & & $\mathrm{F}$ & $P$ & $\mathrm{~F}$ & $P$ & $\mathrm{df}$ & $\mathrm{F}$ & $P$ & $\mathrm{~F}$ & $P$ \\
\hline Season (S) & 3 & 12.6 & $<0.0001$ & 67.5 & $<0.0001$ & 2 & 6.6 & 0.002 & 6.7 & 0.0016 \\
\hline Cropping practice $(\mathrm{CP})$ & 3 & 2.9 & 0.07 & 16.9 & $<0.0001$ & 3 & 2.4 & 0.10 & 14.5 & 0.0003 \\
\hline Variety (V) & 2 & 13.9 & $<0.0001$ & 83.4 & $<0.0001$ & 2 & 6.8 & 0.001 & 14.3 & $<0.0001$ \\
\hline $\mathrm{S} \times \mathrm{CP}$ & 9 & 0.6 & 0.79 & 2.7 & 0.006 & 6 & 1.6 & 0.14 & 9.1 & $<0.0001$ \\
\hline$S \times V$ & 6 & 2.6 & 0.02 & 7.7 & $<0.0001$ & 4 & 0.68 & 0.61 & 1.0 & 0.4159 \\
\hline$C P \times V$ & 6 & 2.4 & 0.03 & 5.1 & $<0.0001$ & 6 & 0.89 & 0.50 & 4.1 & 0.0008 \\
\hline $\mathrm{S} \times \mathrm{CP} \times \mathrm{V}$ & 18 & 0.6 & 0.92 & 1.3 & 0.17 & 12 & 1.1 & 0.35 & 2.7 & 0.0028 \\
\hline
\end{tabular}


Table 2. Means and standard errors of differences (SED) of first S. asiatica emergence date (E-date; in days after sowing, DAS) in rice and maize, following four cropping practices (CP; CONV, CACM, CARB and CAST) and three rice varieties (V; B22, NERICA-9 and NERICA-4) during four cropping season (S1-S4).

\begin{tabular}{|c|c|c|c|c|c|c|c|c|c|c|c|c|c|c|c|c|c|c|c|}
\hline & & \multicolumn{10}{|c|}{ Days to $S$. asiatica emergence in rice (E-date; DAS) } & \multicolumn{8}{|c|}{ Days to $S$. asiatica emergence in maize ( $E$-date; DAS) } \\
\hline & & S1 & & S2 & & S3 & & S4 & & Mean & & S1 & $\mathrm{S} 2$ & & S3 & S4 & & Mean & \\
\hline \multirow{6}{*}{$\begin{array}{l}0 \\
0 \\
x \\
\omega\end{array}$} & CONV & 76.9 & & 72.9 & & 59.9 & & 64.7 & & 68.6 & & - & 55.3 & & 64.4 & 63.0 & & 60.9 & \\
\hline & CACM & 78.9 & & 72.3 & & 65.0 & & 73.3 & & 72.4 & & - & 62.9 & & 71.6 & 63.2 & & 65.9 & \\
\hline & CARB & 77.7 & & 72.9 & & 66.9 & & 68.7 & & 71.6 & & - & 59.1 & & 69.0 & 58.4 & & 62.2 & \\
\hline & CAST & 79.1 & & 78.6 & & 70.3 & & 76.2 & & 76.1 & & - & 64.0 & & 66.2 & 71.3 & & 67.2 & \\
\hline & Mean (S) & 68.6 & $\mathrm{~B}^{1}$ & 72.4 & $A B$ & 71.6 & $\mathrm{~B}$ & 76.1 & A & & & - & 60.3 & $\mathrm{~B}$ & $67.8 \mathrm{~A}$ & 64.0 & $A B$ & & \\
\hline & $\operatorname{LSD}(\mathrm{S})$ & 4.20 & & & & & & & & & & 4.04 & & & & & & & \\
\hline \multirow{5}{*}{$\begin{array}{l}> \\
x \\
\omega\end{array}$} & B22 & 76.1 & $a b c$ & 69.4 & $\mathrm{~cd}$ & 56.7 & $\mathrm{e}$ & 65.8 & $d$ & 67.0 & Z & - & 54.8 & & 65.1 & 60.9 & & 60.3 & $\mathrm{Y}$ \\
\hline & NERICA-9 & 77.8 & $a b$ & 78.8 & $a$ & 63.8 & de & 70.6 & bcd & 72.7 & $\mathrm{Y}$ & - & 62.4 & & 65.4 & 64.1 & & 64.0 & $X Y$ \\
\hline & NERICA-4 & 80.5 & $a$ & 74.3 & $a b c$ & 76.1 & $a b c$ & 75.8 & $a b c$ & 76.7 & $x$ & - & 63.7 & & 72.9 & 66.9 & & 67.8 & $X$ \\
\hline & LSD (V) & 3.64 & & & & & & & & & & 4.04 & & & & & & & \\
\hline & $\operatorname{LSD}(\mathrm{S} \times \mathrm{V})$ & 7.28 & & & & & & & & & & & & & & & & & \\
\hline \multirow{5}{*}{$\begin{array}{l}> \\
\times \\
0\end{array}$} & & CONV & & CACM & & CARB & & CAST & & & & CONV & CACM & & CARB & CAST & & & \\
\hline & B22 & 61.5 & $f$ & 67.3 & def & 65.0 & ef & 74.2 & abcd & & & 59.0 & 59.2 & & 58.2 & 64.7 & & & \\
\hline & NERICA-9 & 68.6 & cdef & 73.9 & abcd & 69.1 & bcde & 79.3 & $a$ & & & 62.4 & 67.2 & & 59.9 & 66.5 & & & \\
\hline & NERICA-4 & 75.7 & $a b c$ & 75.9 & $a b$ & 80.6 & $a$ & 74.6 & $a b c$ & & & 61.2 & 71.4 & & 68.5 & 70.3 & & & \\
\hline & $\operatorname{LSD}(\mathrm{CS} \times \mathrm{V})$ & 7.28 & & & & & & & & & & & & & & & & & \\
\hline
\end{tabular}

${ }^{1}$ Means followed by different letters are significantly different $(P<0.05)$. 
Table 3. Means of maximum aboveground S. asiatica numbers $\left(N \operatorname{Smax} ; \mathrm{m}^{-2}\right)$ in rice and maize, following four cropping practices (CP; CONV, CACM, CARB and CAST) and three rice varieties (V; B22, NERICA-9 and NERICA-4) during four cropping season (S1-S4).

\begin{tabular}{|c|c|c|c|c|c|c|c|c|c|c|c|c|c|c|c|c|c|c|c|c|c|}
\hline & & \multicolumn{10}{|c|}{ Maximum S. asiatica densities in rice (NSmax; plants $\left.\mathrm{m}^{-2}\right)$} & \multicolumn{10}{|c|}{ Maximum S. asiatica densities in maize (NSmax; plants $\left.\mathrm{m}^{-2}\right)$} \\
\hline & & $\mathrm{S} 1^{1}$ & & S2 & & S3 & & S4 & & Mea & & $S 1^{2}$ & & S2 & & S3 & & S4 & & Mean & \\
\hline \multirow{8}{*}{$\begin{array}{l}0 \\
0 \\
\times \\
\infty\end{array}$} & CONV & 0.5 & efgh $^{1}$ & 1.6 & $\mathrm{~cd}$ & 8.7 & $a$ & 1.6 & $\mathrm{~cd}$ & 2.1 & A & 0.05 & & 9.4 & a & 1.7 & bc & 1.9 & $\mathrm{bc}$ & 3.4 & $A^{1}$ \\
\hline & CACM & 0.3 & gh & 0.9 & defg & 5.3 & $\mathrm{~b}$ & 1.9 & c & 1.6 & $B$ & 0.05 & & 1.9 & $\mathrm{bc}$ & 2.1 & $\mathrm{~b}$ & 2.8 & $\mathrm{~b}$ & 2.2 & $B$ \\
\hline & CARB & 0.2 & $\mathrm{~h}$ & 0.5 & fgh & 3.3 & $\mathrm{~b}$ & 1.0 & cdef & 1.0 & $C$ & 0.03 & & 2.7 & $b$ & 1.9 & $\mathrm{bc}$ & 2.0 & $\mathrm{bc}$ & 2.2 & $B$ \\
\hline & CAST & 0.2 & $\mathrm{~h}$ & 0.1 & $\mathrm{~h}$ & 1.3 & cde & 0.4 & fgh & 0.4 & $\mathrm{D}$ & 0.04 & & 0.00 & $d$ & 0.00 & $d$ & 1.0 & C & 0.3 & $\mathrm{C}$ \\
\hline & Mean & 0.28 & 1 & 0.69 & $\mathrm{~J}$ & 3.92 & $\mathrm{~L}$ & 1.14 & $\mathrm{~K}$ & 2.14 & & & & 2.3 & $A$ & 1.2 & $B$ & 1.8 & $A$ & & \\
\hline & LSD (S) & 0.22 & & & & & & & & & & 0.23 & & & & & & & & & \\
\hline & LSD (CS) & 0.22 & & & & & & & & & & 0.27 & & & & & & & & & \\
\hline & LSD (S×CS) & 0.48 & & & & & & & & & & 0.52 & & & & & & & & & \\
\hline \multirow{5}{*}{$\begin{array}{l}> \\
\times \\
\omega\end{array}$} & B22 & 0.66 & def & 1.5 & $\mathrm{C}$ & 12.2 & $a$ & 2.9 & $\mathrm{~b}$ & 2.8 & $A$ & & & 3.7 & & 1.59 & & 2.4 & & 2.5 & $A$ \\
\hline & NERICA-9 & 0.20 & $\mathrm{fg}$ & 0.9 & $\mathrm{~cd}$ & 4.1 & $b$ & 1.0 & $\mathrm{~cd}$ & 1.2 & $\mathrm{~B}$ & & & 2.6 & & 1.57 & & 1.9 & & 2 & $A$ \\
\hline & NERICA-4 & 0.1 & g & 0.1 & $\mathrm{~g}$ & 0.8 & de & 0.3 & efg & 0.3 & $\mathrm{C}$ & & & 1.1 & & 0.65 & & 1.3 & & 1 & $B$ \\
\hline & LSD (V) & 0.19 & & \multicolumn{18}{|c|}{0.23} \\
\hline & $\operatorname{LSD}(\mathrm{S} \times \mathrm{V})$ & 0.41 & & & & & & & & & & & & & & & & & & & \\
\hline \multirow{5}{*}{$\begin{array}{l}> \\
\times \\
\mathcal{N}\end{array}$} & & CONV & & CACM & & CARB & & CAST & & & & CONV & & CACM & & CARB & & CAST & & & \\
\hline & B22 & 6.1 & a & 4.1 & $a$ & 2.1 & $\mathrm{~b}$ & 0.9 & $\mathrm{~cd}$ & & & 7.0 & $a$ & 2.7 & bcd & 2.5 & bcd & 0.4 & $\mathrm{fg}$ & & \\
\hline & NERICA-9 & 2.2 & $\mathrm{~b}$ & 1.6 & $\mathrm{bc}$ & 1.2 & $\mathrm{C}$ & 0.3 & e & & & 3.1 & $\mathrm{bc}$ & 2.2 & bcd & 3.9 & $b$ & 0.2 & g & & \\
\hline & NERICA-4 & 0.4 & de & 0.3 & e & 0.1 & e & 0.2 & e & & & 1.5 & $\mathrm{~cd}$ & 1.8 & cde & 0.9 & ef & 0.2 & $g$ & & \\
\hline & $\operatorname{LSD}(\mathrm{CS} \times \mathrm{V})$ & \multicolumn{2}{|c|}{0.41} & \multicolumn{18}{|c|}{0.52} \\
\hline
\end{tabular}

\footnotetext{
${ }^{1}$ Means and LSD values are back-transformed after analysis; means followed by different letters are significantly different $(P<0.05) .{ }^{2}$ No rice variety factor in $\mathrm{S} 1$
} 
Table 4. Results of the three-stage analysis of $S$. asiatica seed numbers in the soil, following a negative binomial distribution with 1 . Analysis of Co-variance (ANCOVA), 2. Analysis of variance (ANOVA), and 3. Comparison of means (Tukey's). Rice variety (V), cropping practice (CP), seed numbers at the start of the experiment ( $\mathrm{S} 0)$, and interactions are sources of variation in the ANCOVA, and rice variety $(\mathrm{V})$, cropping practice $(\mathrm{CP})$ and interactions are sources of variation in the ANOVA. Means of $S$. asiatica seed numbers in the soil at $0-10 \mathrm{~cm}$ depth (seeds $\mathrm{m}^{-2}$ ), are compared across four cropping practices (CP; CONV, CACM, CARB and CAST).

\begin{tabular}{|c|c|c|c|c|}
\hline Analysis & Effect & df & $\mathrm{F}$ & $P$ \\
\hline \multirow[t]{7}{*}{ 1. ANCOVA } & Variety (V) & 2 & 3.61 & 0.04 \\
\hline & Cropping Practice (CP) & 3 & 11.04 & 0.00 \\
\hline & $\mathrm{V} \times \mathrm{CP}$ & 6 & 0.74 & 0.62 \\
\hline & Seed \# at start (SO) & 1 & 0.34 & 0.56 \\
\hline & $\mathrm{SO} \times \mathrm{V}$ & 2 & 0.53 & 0.60 \\
\hline & $\mathrm{SO} \times \mathrm{CP}$ & 3 & 0.95 & 0.43 \\
\hline & $\mathrm{SO} \times \mathrm{V} \times \mathrm{CP}$ & 6 & 1.25 & 0.31 \\
\hline \multirow[t]{4}{*}{ 2. ANOVA } & Variety (V) & 2 & 1.77 & 0.18 \\
\hline & Cropping Practice (CP) & 3 & 9.77 & $<0.0001$ \\
\hline & $\mathrm{V} \times \mathrm{CP}$ & 6 & 0.89 & 0.51 \\
\hline & Cropping Practice & \multicolumn{3}{|c|}{ S. asiatica seed number $\mathrm{m}^{-2}(0-10 \mathrm{~cm})$} \\
\hline \multirow[t]{4}{*}{ 3. Comparison of means } & CONV & \multicolumn{3}{|c|}{$8022 a^{1}$} \\
\hline & CACM & \multicolumn{3}{|c|}{$1943 b$} \\
\hline & CAST & \multicolumn{3}{|c|}{$1725 b$} \\
\hline & CARB & \multicolumn{3}{|c|}{$1098 \mathrm{~b}$} \\
\hline
\end{tabular}

${ }^{1}$ Means followed by different letters are significantly different $(P<0.0001)$ 


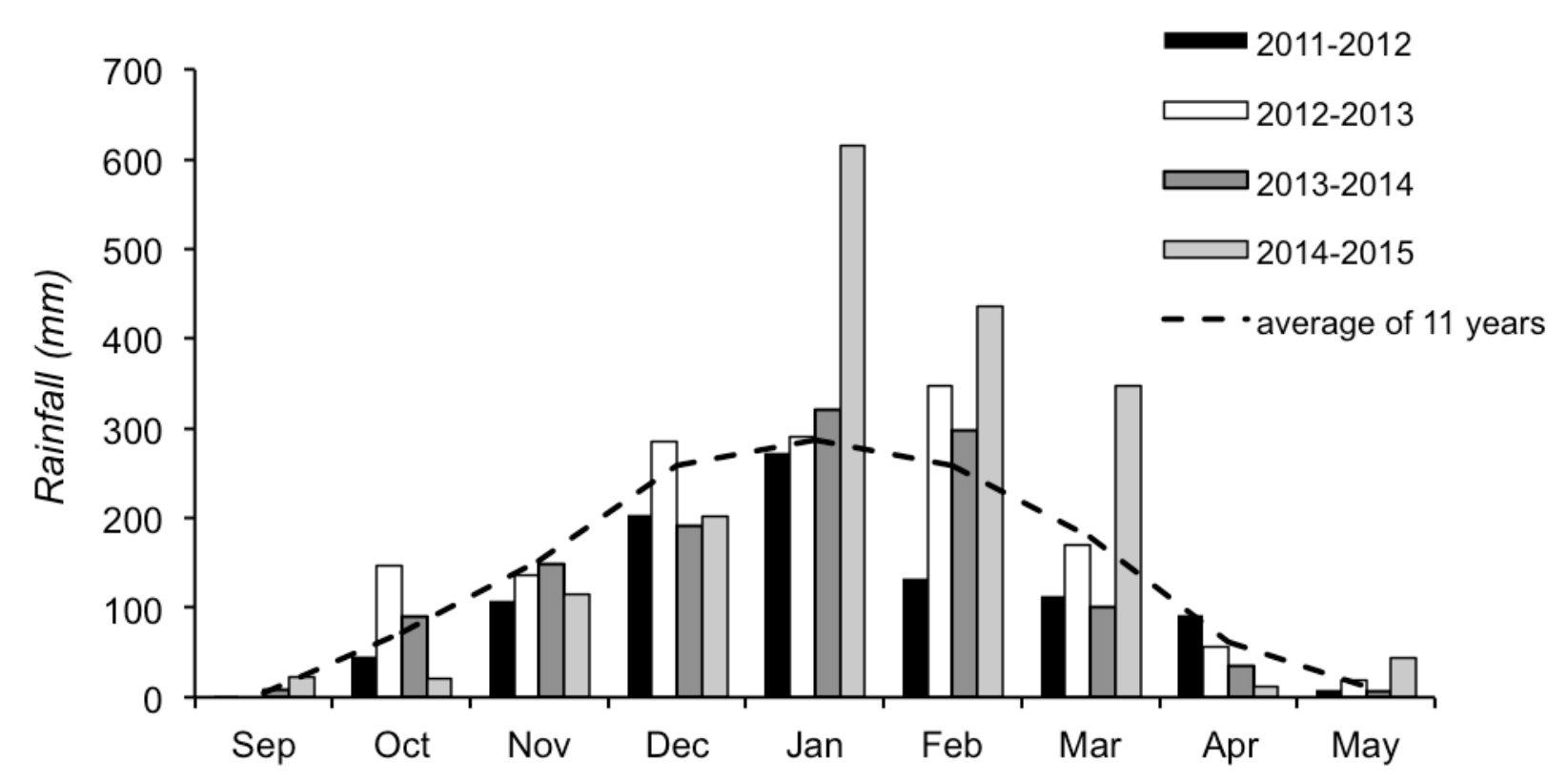

\section{Months covering the cropping season}

Figure 1. Monthly rainfall (mm) per season, during the four cropping seasons from 2011-2012 (S1) to 2014-2015 (S4), and the 11-year average. 
$\square$ Weeding intervention 1

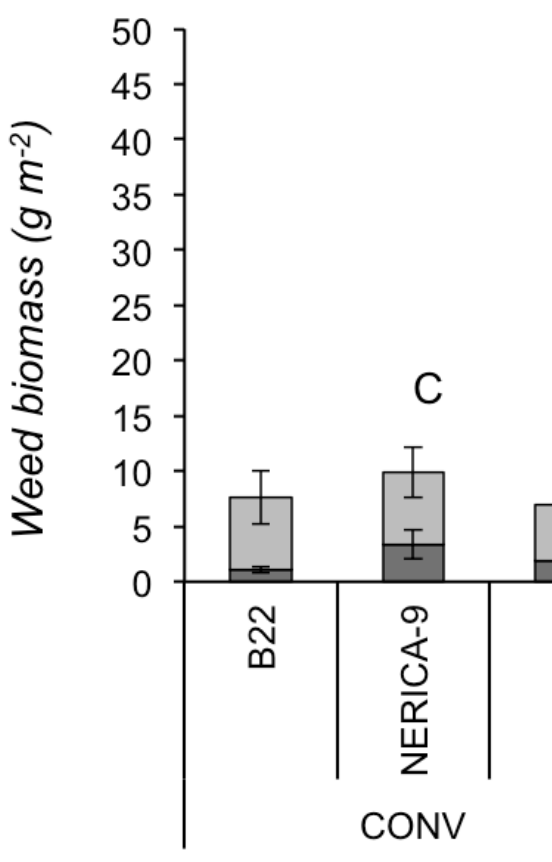

A

$\square$ Weeding intervention 2

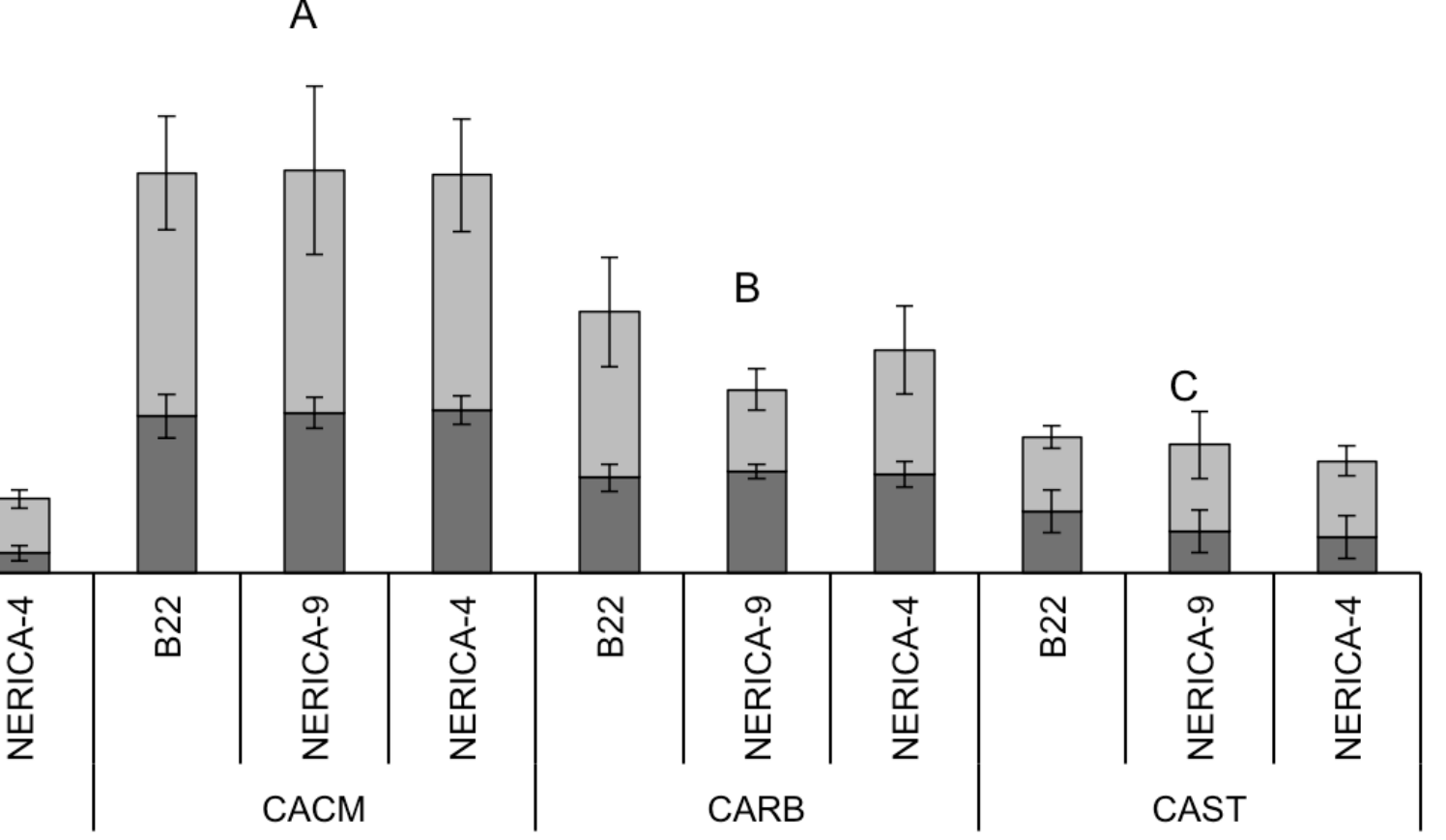

Varieties and cropping practices

Figure 2. Weed biomass dry weight in season 4 with weeding time (Dark grey: W1; Light grey: W2), cropping practice (CONV, CACM, CARB, CAST), rice variety (B22, NERICA-9, NERICA-4) as factors. Comparison of means conducted on total (W1 and W2 samplings) weed biomass dry weights per cropping practice $\left(\right.$ WBtot $\left.; \mathrm{g} \mathrm{m}^{-2}\right)$. Different letters $(\mathrm{A}, \mathrm{B}, \mathrm{C})$ indicate significant differences $(P<0.0001)$. 


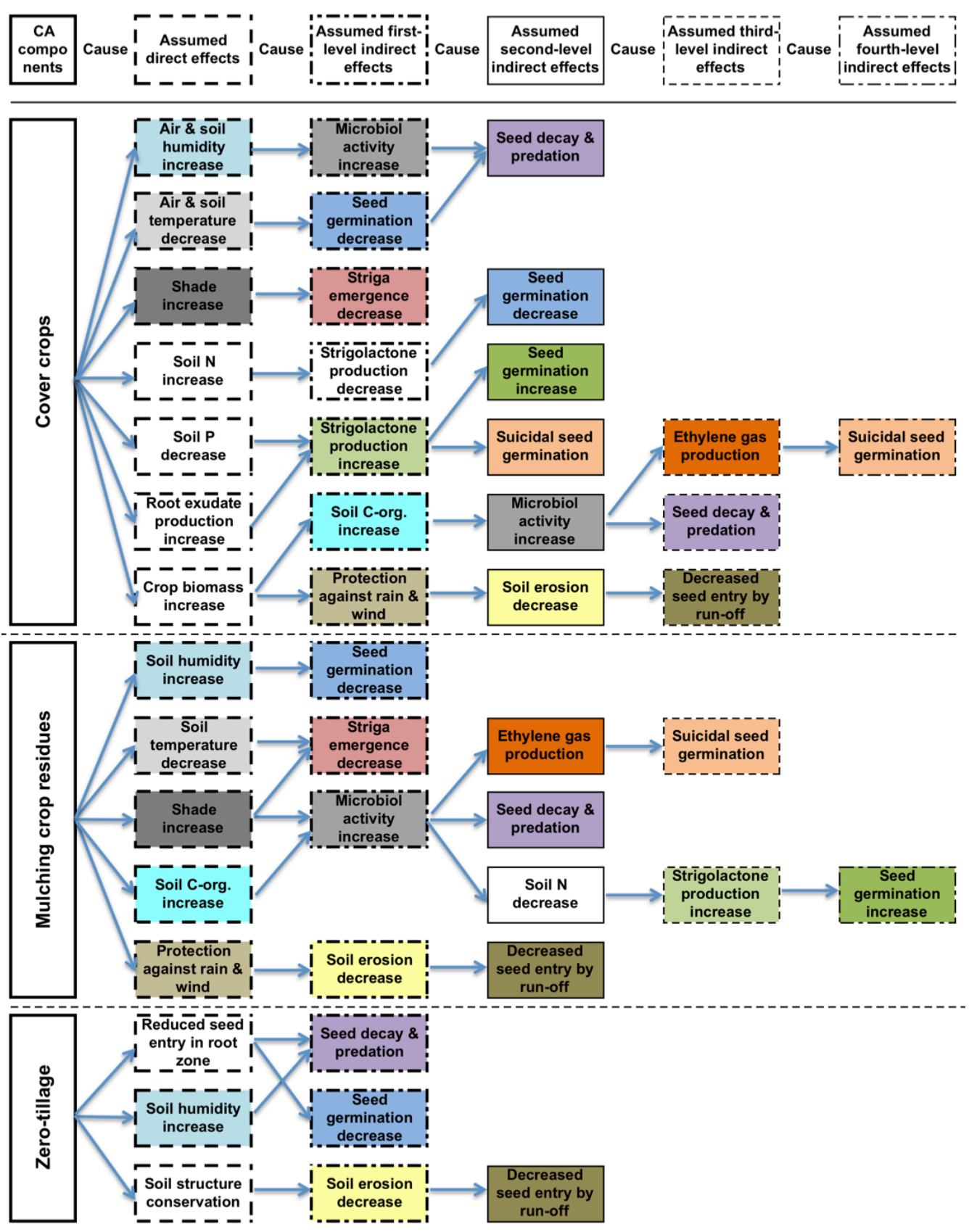

Figure 3. Assumed direct and indirect causal relations between Conservation Agriculture (CA) components - cover crops, crop residue mulching and zero-tillage - and $S$. asiatica. Boxes with the same border style indicate the same level in process. Boxes of the same color indicate the same assumed effect. 